\title{
Efisiensi Rem Kendaraan Isuzu TLD 24 C Dengan Variasi Beban Dan Tekanan Angin Ban
}

\author{
Nur Halimatus Sa'diyah ${ }^{1}$, Herman Mariadi Kaharmen ${ }^{2}$, Siti Shofiah ${ }^{3}$ \\ ${ }^{1}$ Program Studi Pengujian Kendaraan Bermotor, Politeknik Keselamatan Transportasi Jalan \\ E-mail: nurhalimatus709@gmail.com
}

Received 24 September 2020; Reviewed 24 Oktober 2020; Accepted 9 November 2020 Journal Homepage: http://ktj.pktj.ac.id/index.php/ktj

DOI: $10.46447 / k t j . v 7 i 2.208$

\begin{abstract}
Abstrak
Kendaraan adalah suatu sarana angkut di jalan yang terdiri atas kendaraan bermotor dan kendaraan tidak bermotor sesuai dengan PP nomor 55 tahun 2012 pasal 1. Tekanan angin ban yang kurang pada kendaraan menimbulkan dampak negatif yaitu pengereman tidak maksimal. Penelitian ini membahas pengaruh perbedaan tekanan angin ban terhadap hasil pengujian rem di UPTD Pengujian Kendaraan Bermotor Wiyung Kota Surabaya, pada mobil barang Isuzu TLD $24 \mathrm{C}$ bak terbuka menggunakan alat uji brake tester guna menentukan nilai pengaruh perbedaan tekanan ban terhadap efisiensi pengereman. Metode yang digunakan eksperimental pada kendaraan tanpa beban, beban $<10 \%$ JBI dan beban $>10 \%$ JBI. Efisiensi rem paling besar bernilai $80.5 \%$ dan paling kecil bernilai $41 \%$. Nilai efisiensi rem kendaraan tanpa beban terdapat penyimpangan besar, sumbu 1 bernilai $18.8 \%$ dan sumbu 2 bernilai $8.5 \%$. Keduanya tidak memenuhi standar yang ditetapkan JIS. Oleh karena itu, perlunya peninjauan kembali pada PM 134 tahun 2015 pasal 26 ayat 6 mengenai toleransi pemuatan beban kendaraan dan PP nomor 55 tahun 2012 pasal 67 ayat 1 mengenai kelulusan pengujian rem tidak hanya mencantumkan efisiensi rem tetapi juga mencantumkan peraturan mengenai penyimpangan rem pada kendaraan agar tidak membahayakan keselamatan di jalan.
\end{abstract}

Kata Kunci : Efisiensi rem, Isuzu TLD 24 C, brake tester

\section{PENDAHULUAN}

Transportasi saat ini menjadi kebutuhan yang sangat vital bagi setiap orang, sejalan dengan meningkatnya mobilitas setiap individu di zaman global ini maka sarana transportasi pun mengalami kemajuan dari waktu ke waktu, dimana di setiap perubahannya terdapat penyempurnaan dari versi sebelumnya. Hal ini yang menyebabkan jumlah kendaraan menjadi semakin meningkat pada setiap tahunnya. Terjadinya kecelakaan biasanya banyak terjadi dari kendaraan wajib uji, dalam pemeriksaan investigasi lapangan disebutkan bahwa penyebabnya karena sistem rem yang kurang berfungsi dengan semestinya. Faktor-faktor keselamatan pun dikesampingkan karena banyak pemilik kendaraan yang menginginkan biaya transportasi seminimal mungkin dengan untung tinggi. Ban adalah bagian penting dari kendaraan darat yang digunakan untuk mengurangi getaran yang disebabkan ketidakteraturan permukaan jalan, melindungi roda dari aus dan kerusakan, serta memberikan kestabilan antara kendaraan dan tanah untuk meningkatkan percepatan dan mempermudah pergerakan. 
Tekanan angin ban yang kurang pada kendaraan menimbulkan dampak negatif yaitu pengereman tidak maksimal.

Tekanan angin ban yang rendah pada pengujian drum test menghasilkan performance ban yang jelek (Handoyo, 2014). Tekanan ban terhadap besarnya rolling resistance dipengaruhi oleh peningkatan tekanan udara (inflation preassure) dan semakin tinggi tekanan udara pada ban akan semakin kecil lebar tapak ban (Muttaqin, 2015). Besarnya inflated pressure yang diterapkan ke ban tipe radial berbanding terbalik dan memiliki grafik segaris dengan nilai rolling resistance coefficient (Setiyana, 2013). Sedangkan, tekanan angin ban yang berbeda-beda dapat mempengaruhi efisiensi dan penyimpangan rem (Sucahyo, 2019). Pada pelaksanaan pengujian di UPTD Pengujian Kendaraan Bermotor Wiyung Kota Surabaya banyak tekanan angin ban yang tidak sesuai standar. Oleh karena itu, dalam penelitian ini akan dibahas mengenai hasil pengujian rem dengan variasi tekanan angin ban terhadap sumbu 1 dan sumbu 2 kendaraan di UPTD Pengujian Kendaraan Bermotor Wiyung Kota Surabaya.

\section{METODE PENELITIAN}

Metode penelitian yang digunakan adalah eksperimen. Bahan yang digunakan dalam penelitian ini yaitu Isuzu TLD $24 \mathrm{C}$ dan ban. Alat yang digunakan dalam penelitian ini yaitu brake tester merek Iyasaka dan alat ukur tekanan ban (tyre pressure gauge). Data primer dalam penelitian ini yaitu menguji rem menggunakan brake tester dengan kondisi tekanan ban kurang dari standar, tekanan ban sesuai standar, tekanan ban lebih dari standar. Data sekunder dalam penelitian ini yaitu berdasarkan perundang-undangan, manual book, buku uji kendaraan Isuzu TLD $24 \mathrm{C}$ bak terbuka. Variasi tekanan angin ban yang digunakan pada sumbu 1 yaitu 35 psi, 40 psi, 45 psi, 50 psi, 55 psi, 60 psi sedangkan pada sumbu 2 yaitu 50 psi, 55 psi, 60 psi, 65 psi, 70 psi, 75 psi. Setelah tekanan angin ban divariasikan kemudian dilakukan pengujian rem menggunakan brake tester. Hasil dari pengujian rem dihitung efisiensinya menggunakan rumus :

$$
\eta S b=\frac{\text { Jumlahgayarempdsumbu }(S 1+S 2)}{B K(S 1+S 2)} \times 100 \%
$$

dimana $\eta S b$ merupakan efisiensi rem (\%), S1 merupakan sumbu $1(\mathrm{~N}), S 2$ merupakan sumbu $2(\mathrm{~N}), B K$ merupakan berat kendaraan $(\mathrm{kg})$. Untuk kode tekanan angin ban dapat dilihat pada Tabel 1 .

Tabel 1. Kode Beserta Keterangan Tekanan Angin Ban pada Grafik

\begin{tabular}{ccc}
\hline No. & Kode & $\begin{array}{c}\text { Tekanan Angin Ban Sumbu 1 dan } \\
\text { Sumbu 2 (psi) }\end{array}$ \\
\hline 1 & $\mathrm{~S}_{1} 35 \mathrm{~S}_{2} 50$ & 35 dan 50 \\
2 & $\mathrm{~S}_{1} 40 \mathrm{~S}_{2} 55$ & 40 dan 55 \\
3 & $\mathrm{~S}_{1} 45 \mathrm{~S}_{2} 60$ & 45 dan 60 \\
4 & $\mathrm{~S}_{1} 50 \mathrm{~S}_{2} 65$ & 50 dan 65 \\
5 & $\mathrm{~S}_{1} 55 \mathrm{~S}_{2} 70$ & 55 dan 70 \\
6 & $\mathrm{~S}_{1} 60 \mathrm{~S}_{2} 75$ & 60 dan 75 \\
\hline
\end{tabular}




\section{HASIL DAN PEMBAHASAN}

Hasil perhitungan efisiensi rem pada kendaraan tanpa beban dan kendaraan dengan beban disesuaikan dengan standar efisiensi rem pada PP No. 55 Tahun 2012 pasal 67 ayat 1 yang menyatakan bahwa adanya pengukuran efisiensi sistem rem utama perlambatan paling sedikit $5 \mathrm{~m} / \mathrm{s}^{2}(50 \%)$.

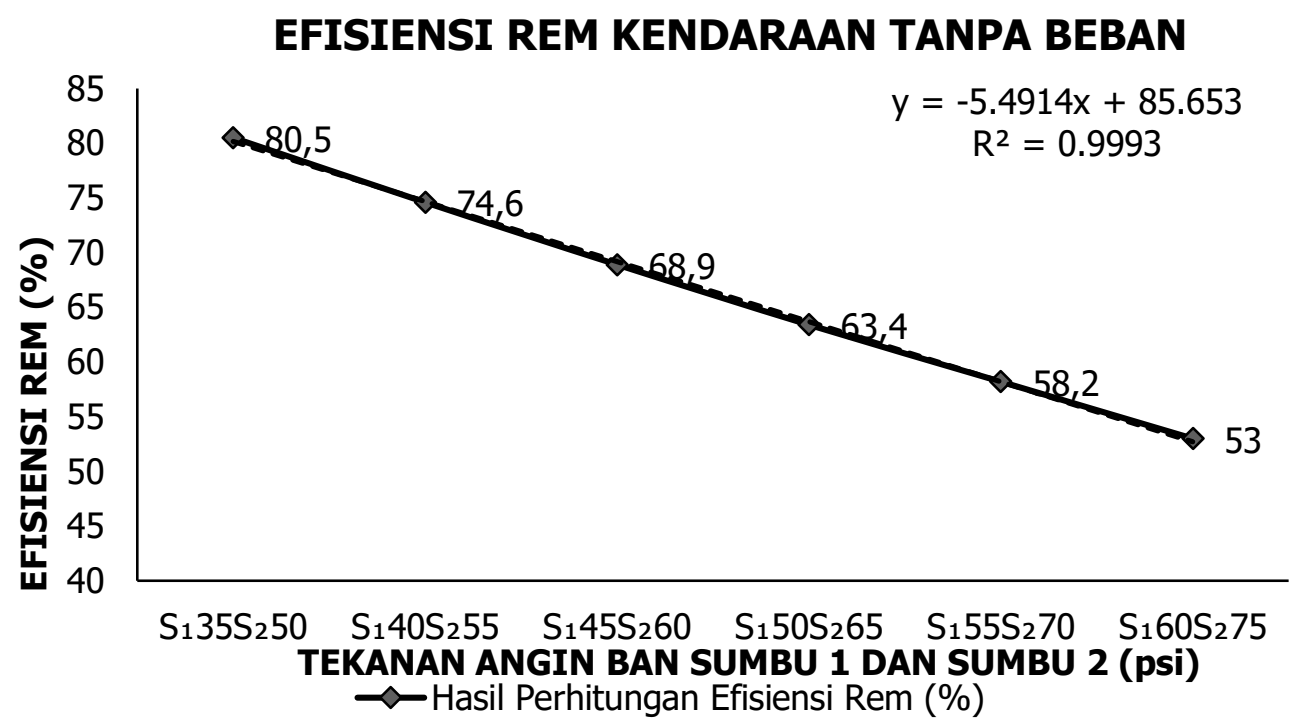

Gambar 1. Grafik Efisiensi Rem Kendaraan Tanpa Beban

Pada Gambar 1. dapat dilihat bahwa besarnya efisiensi rem menunjukkan tren yang terus menurun pada setiap kenaikan tekanan angin ban. Diperoleh nilai efisiensi rem yang memenuhi standar yaitu $\mathrm{S}_{1} 35 \mathrm{~S}_{2} 50$ dengan nilai $80.5 \%$, $\mathrm{S}_{1} 40 \mathrm{~S}_{2} 55$ dengan nilai $74.6 \%, \mathrm{~S}_{1} 45 \mathrm{~S}_{2} 60$ dengan nilai $68.9 \%, \mathrm{~S}_{1} 50 \mathrm{~S}_{2} 65$ dengan nilai $63.4 \%, \mathrm{~S}_{1} 55 \mathrm{~S}_{2} 70$ dengan nilai $58.2 \%, \mathrm{~S}_{1} 60 \mathrm{~S}_{2} 75$ dengan nilai $53 \%$.

\section{EFISIENSI REM KENDARAAN DENGAN BEBAN}

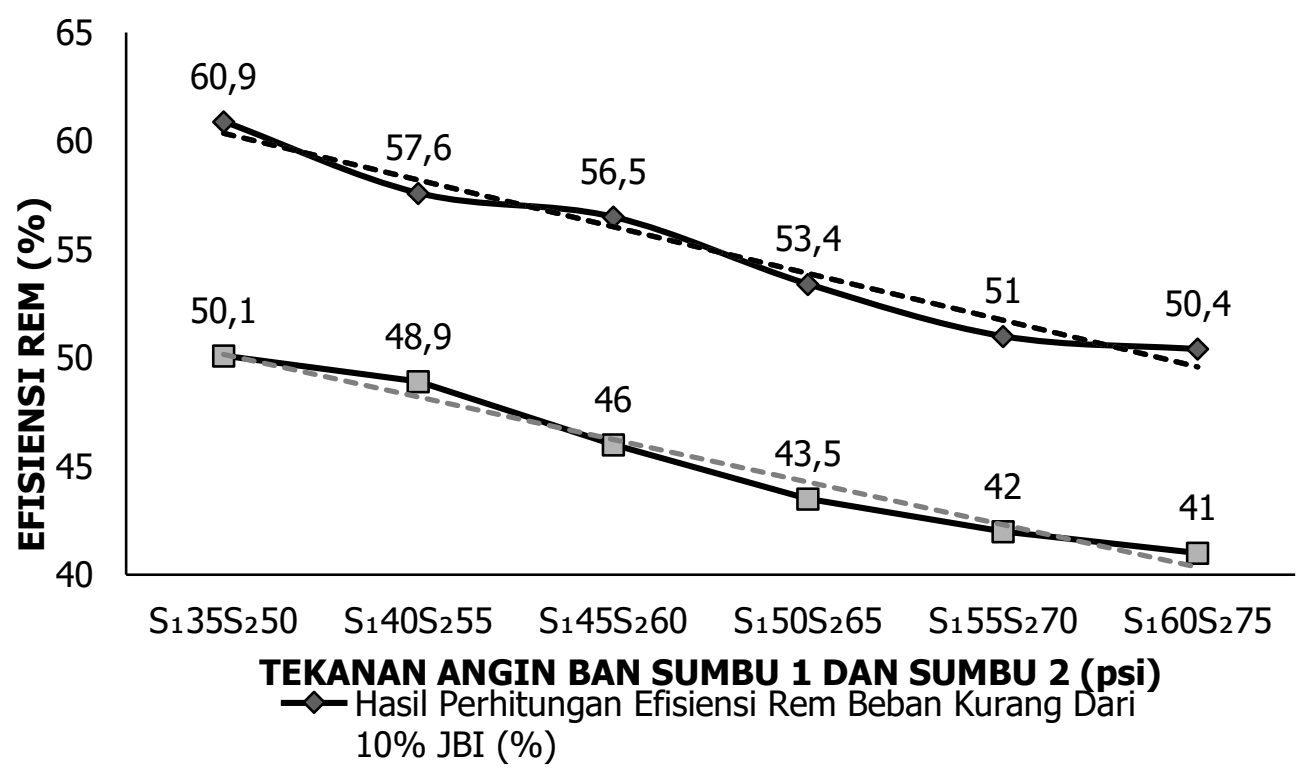

Gambar 2. Grafik Efisiensi Rem Kendaraan dengan Beban 
Pada Gambar 2. dapat dilihat bahwa grafik efisiensi kendaraan dengan beban mengalami penurunan. Nilai efisiensi rem yang memenuhi standar yaitu $\mathrm{S}_{1} 35 \mathrm{~S}_{2} 50$ dengan nilai $60.9 \%, \mathrm{~S}_{1} 40 \mathrm{~S}_{2} 55$ dengan nilai $57.6 \%, \mathrm{~S}_{1} 45 \mathrm{~S}_{2} 60$ dengan nilai $56.5 \%, \mathrm{~S}_{1} 50 \mathrm{~S}_{2} 65$ dengan nilai $53.4 \%, \mathrm{~S}_{1} 55 \mathrm{~S}_{2} 70$ dengan nilai $51 \%, \mathrm{~S}_{1} 60 \mathrm{~S}_{2} 75$ dengan nilai $50.4 \%$ untuk kendaraan dengan beban kurang dari $10 \%$ JBI. Nilai efisiensi rem yang memenuhi standar yaitu $\mathrm{S}_{1} 35 \mathrm{~S}_{2} 50$ dengan nilai $50.1 \%$ untuk kendaraan dengan beban lebih dari $10 \%$ JBI. Dari grafik efisiensi rem kendaraan tanpa beban maupun kendaraan dengan beban kurang dari 10\% JBI atau lebih dari 10\% JBI menunjukkan bahwa semakin besar tekanan angin ban maka semakin kecil efisiensi rem yang dihasilkan sedangkan semakin kecil tekanan angin ban maka semakin besar efisiensi rem yang dihasilkan.

Berdasarkan PM 134 Tahun 2015 pasal 26 ayat 6 yang menyatakan bahwa kelebihan berat muatan atau muatan pada tiap-tiap sumbu sampai dengan $5 \%$ (lima persen) dari yang ditetapkan, tidak dinyatakan pelanggaran. Sedangkan pada penelitian yang telah dilakukan muatan lebih dari $10 \% \mathrm{JBI}$, sehingga dinyatakan pelanggaran. Berdasarkan penyimpangan rem pada dasar teknis pengujian berkala yaitu maksimal $8 \%$ (standar JIS). JIS (Japanese Industrial Standards) menetapkan standar yang digunakan untuk kegiatan industri di Jepang. Pada penelitian yang telah dilakukan penyimpangan rem sumbu 1 yaitu $18.8 \%$ dan penyimpangan rem sumbu 2 yaitu $8.5 \%$ pada kendaraan tanpa beban. Pada sumbu 1 dan sumbu 2 terdapat penyimpangan rem yang besar dan tidak memenuhi standar penyimpangan rem. Akibat yang ditimbulkan dari penyimpangan rem yang besar yaitu terjadinya slip kendaraan pada arah lateral (ke arah samping) atau koefisien gesek antara ban dengan jalan pada arah lateral nol sehingga kendaraan akan terlempar ke kanan atau ke kiri.

\section{SIMPULAN}

Berdasarkan data dan analisis yang dilakukan dapat ditarik kesimpulan : (a) Perbedaan tekanan angin ban berpengaruh terhadap efisiensi rem pada saat pengujian brake tester, karena semakin besar tekanan angin ban maka semakin kecil efisiensi rem yang dihasilkan sedangkan semakin kecil tekanan angin ban maka semakin besar efisiensi rem yang dihasilkan; (b) Hasil pengujian brake tester pada kendaraan tanpa beban melebihi standar JIS yaitu 8\%; (c) Hasil efisiensi rem kendaraan dengan beban lebih dari 10\% JBI kurang dari 50\% (standar) dan tidak memenuhi kelaikan jalan.

\section{SARAN}

Diperlukan penelitian lanjutan untuk penguji kendaraan bermotor seharusnya sebelum pra uji melakukan kegiatan tambahan berupa mengukur tekanan angin ban, untuk kelulusan pengujian brake tester dalam PP Nomor 55 Tahun 2012 pasal 67 ayat 1 tidak hanya mencantumkan efisiensi rem saja tetapi perlu ditambahkan peraturan mengenai penyimpangan rem sehingga perlunya revisi dalam peraturan tersebut dan untuk pemuatan beban yang ada di PM 134 Tahun 2015 pasal 26 ayat 6 mengenai toleransi beban muatan sebesar $5 \%$ pada setiap sumbu perlu adanya peninjauan kembali agar tidak membahayakan keselamatan pada saat di jalan. 


\section{DAFTAR PUSTAKA}

Handoyo, Y. (2014). Analisis Performance Ban Dengan Alat Drum Test. Jurnal IImiah Teknik Mesin Unisma "45" Bekasi.

https://www.ilmubeton.com/2018/07/mengenal-jis-japanese-industrial.html

Menteri Perhubungan Republik Indonesia. (2015). Peraturan Menteri Perhubungan Republik Indonesia Nomor PM 134 Tahun 2015 tentang Penyelenggaraan Penimbangan Kendaraan Bermotor di Jalan.

Muttaqin, M. M. (2015). Pengaruh Tekanan Udara (Inflation Preassure) pada Tipe Radial Ply Terhadap Rolling Resistance.

Presiden Republik Indonesia. (2012). Peraturan Pemerintah Republik Indonesia Nomor 55 Tahun 2012 tentang Kendaraan.

Setiyana, B. (2013). Pengaruh Tekanan dan Beban Ban pada Ban Tipe Radial Terhadap Rolling Resistance Kendaraan Penumpang. Journal of Chemical Information and Modeling.

Sucahyo, V. I. (2019). Perbedaan Tekanan Angin Ban Berpengaruh Terhadap Hasil Pengujian Rem di UPTD Pengujian Kendaraan Bermotor Kabupaten Jombang (Studi Kasus Mitsubishi Colt L300). 